\title{
ARGIRÓPOLIS, ORBIS TERTIUS. LA EDUCACIÓN COMO UNA IDEA, Y LA IDEA COMO UN DESTINO
}

\section{ARGIRÓPOLIS, ORBIS TERTIUS. EDUCATION AS AN IDEA, AND THE IDEA AS A DESTINATION}

\section{MAXIMILIANO FABI}

Profesor de Historia por la Universidad Nacional de La Plata (UNLP). Miembro del Centro DescartesCentro de enseñanza e investigación asociado al Instituto del Campo Freudiano-. Autor de Cuadernos de sí y de no, Otium ediciones (2016). Fue director del Colegio III Milenio de La Plata y actualmente se desempeña como docente en distintos establecimientos educativos de la Ciudad Autónoma de Buenos Aires.

Resumen: Ensayo de historia acerca del normalismo en Argentina, a partir de las figuras de Raquel Camaña, Mary Olstine Graham y Domingo Faustino Sarmiento.

Palabras claves: Raquel Camaña - Mary Graham - Sarmiento
Abstract: Historical essay about normalism in Argentina, from the figures of Raquel Camaña, Mary Olstine Graham and Domingo Faustino Sarmiento. Key words: Raquel Camaña - Mary Graham Sarmiento

“QQué obstáculos impedirían que la idea se convirtiese en hecho práctico, que el deseo se tornase realidad?" D. F. Sarmiento, Argirópolis

"Los años me convencieron de que los sueños son un destino, imágenes de la fatalidad". Germán García, Perdido 
“(...) Con verdadera fe en el poder de la «verdad natural” como educadora, pues he observado en mí sus efectos bajo la genial dirección de Miss Mary O. Graham en la Escuela Normal de La Plata, quise hacer todo lo posible por difundir ese «espíritu de enseñanza» entre nosotros y solicité en la Facultad de Filosofía y Letras la suplencia de la cátedra de Ciencia de la Educación con el solo objeto de dictar un curso sobre «educación e instrucción sexual».

Con gran sorpresa de mi parte, se me niega el derecho a presentarme a concurso para optar la suplencia por el solo hecho de «que soy mujer».

Y, como la Facultad es autónoma, aunque tenga a mi favor opiniones autorizadas como la del Excelentísimo señor Ministro de Justicia, doctor Garro, preveo que, difícilmente, el Consejo Superior Universitario, al que he recurrido en última instancia, solucionará «el asunto» en justicia.

¿Cómo hablar de «libertad de enseñanza» en un país donde los puestos educacionales no son accesibles a todos sin otra condición previa que la idoneidad?”

(1) Raquel Camaña, "El prejuicio sexual" y el profesorado en la Facultad de Filosofía y Letras 1910

I.

Interrogarse acerca de la posibilidad de estas palabras en el XXXVII tomo de la Revista de Derecho, Historia y Letras que fundara Estanislao Zeballos en 1898, es -de alguna manera- intentar aproximar un imposible. De las innúmeras condiciones históricas, ensayemos abstraer al menos una, no ojalá la menos cardinal.

26 Claro que Raquel Camaña (educadora y escritora argentina que moriría en 1915, con tan sólo 32 años de edad) ya se encarga allí de deslizar aquel factor al mentar a Mary O. Graham, una de las "maestras norteamericanas" que fueran convocadas por Domingo Faustino Sarmiento a partir de 1869, y al respecto de la cual el propio Sarmiento dijera alguna vez que "he dado a San Juan lo mejor que podía mandándoles a Miss Mary O. Graham"2.
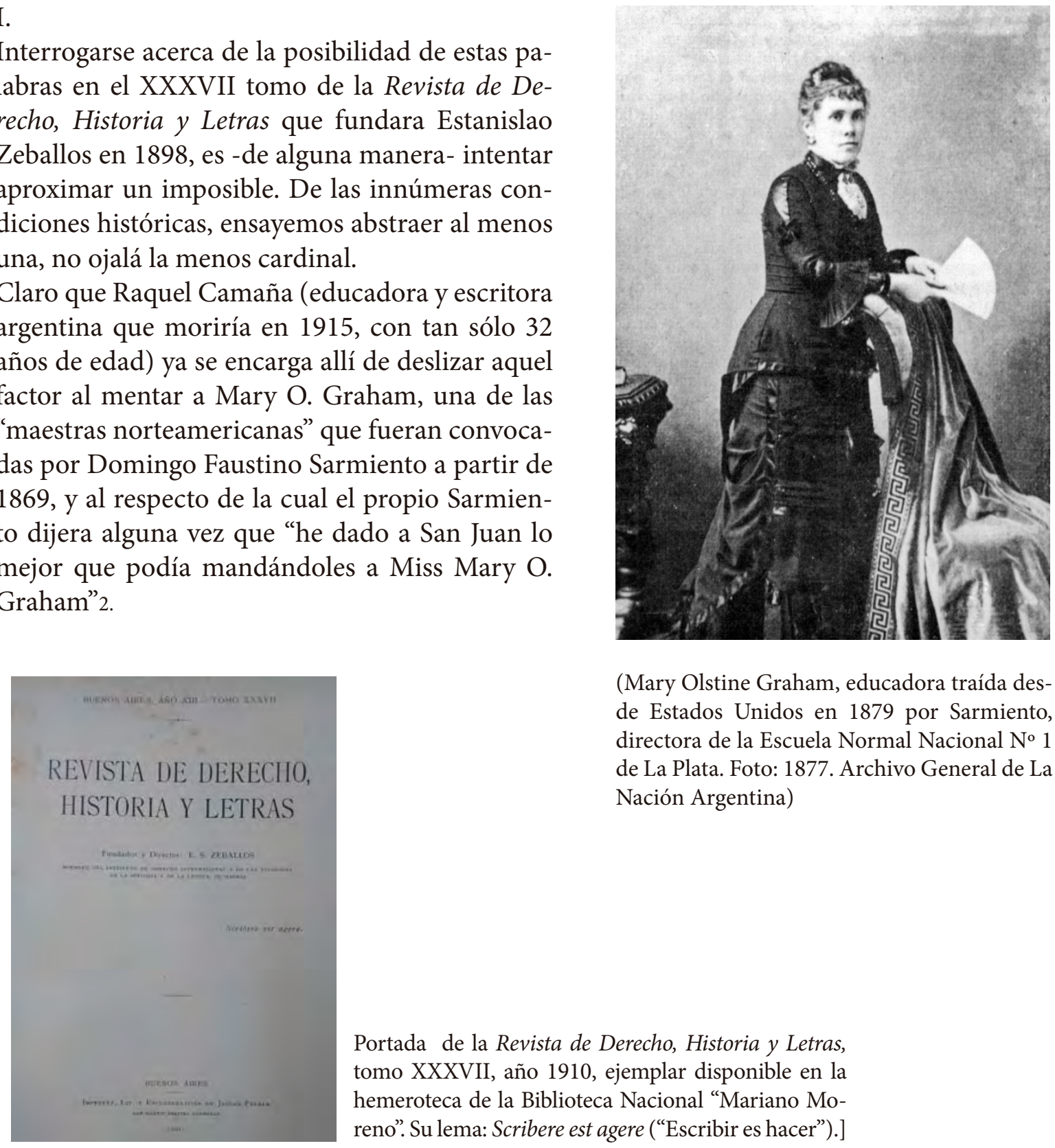

(Mary Olstine Graham, educadora traída desde Estados Unidos en 1879 por Sarmiento, directora de la Escuela Normal Nacional No 1 de La Plata. Foto: 1877. Archivo General de La Nación Argentina)

Portada de la Revista de Derecho, Historia y Letras, tomo XXXVII, año 1910, ejemplar disponible en la hemeroteca de la Biblioteca Nacional "Mariano Moreno". Su lema: Scribere est agere (“Escribir es hacer”).]

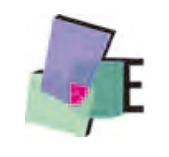


En efecto, Mary Olstine Graham llegaría a la Argentina unos diez años después de comenzada aquella empresa pedagógica. El primer objetivo de su convocatoria fue hacerse cargo de la entonces flamante Escuela Normal de San Juan, aunque algún tiempo después (sería 1.887) se le encomendaría la dirección de la que ahora es la Escuela Normal No 1 de La Plata. Este establecimiento hoy funde su nombre con el de su primera directora, pero lo cierto es que no llegaría a funcionar donde lo hace actualmente sino hasta 1923.

De ahí que no fuese en las aulas que muy probablemente imaginaríamos sino en las de su anterior y primera sede (el actual Liceo Víctor Mercante), donde Raquel Camaña iría a encontrarse con la enseñanza de Miss Graham. De ambas (transmisión y persona) luego nos dejaría sendas páginas elogiosas, pero de todo aquello que $\mathrm{Ca}$ maña iba a denominar allí "el espíritu de su enseñanza", refiramos únicamente este fragmento: "Hace poco -escribía-, cuando lo hice conocer en una de las sesiones plenas del Congreso Internacional de Higiene Escolar reunido en París, la asamblea escuchaba absorta y conmovida, como ante un ideal futuro, el relato de lo que, para mí era -desgraciadamente- una bellísima y fecunda realidad vivida ya"3. Después de todo, acaso esta imagen -si fuese posible ver más allá de lo fascinante- sirva para transmitir todo lo que de una promesa (y por lo tanto de memoria, que es deuda, y de ahí toda la cultura) va de suyo, siempre, en la tarea educativa.

II.

Pensar la serie que a partir de Raquel Camaña, se pierde en aquel viejo futuro que -como las aguas del río que imaginara Merleau- nos trae a Mary Olstine Graham y Domingo Faustino Sarmiento, es pensar en la historia de la educación; y en ese sentido es también pensar en la lenta erosión de una de las ideas más nobles e ingenuas que aquel fantasma llamado "humanidad" pudo alguna vez haber pergeñado: la idea de que el Hombre (así dicho, universalmente) era perfectible a través de la instrucción, y que con la debida educación, cualquiera podía llegar a ser tan virtuoso como Sócrates. Esa idea -como todas- tuvo su aquí y su ahora, y puede que no sea exagerado sugerir que su limitada ubicuidad deba corresponderse con Europa entre los siglos XVIII y XIX. Esa idea, además, supo legarnos una institución: la escuela. Sarmiento se propuso una tarea monumental:

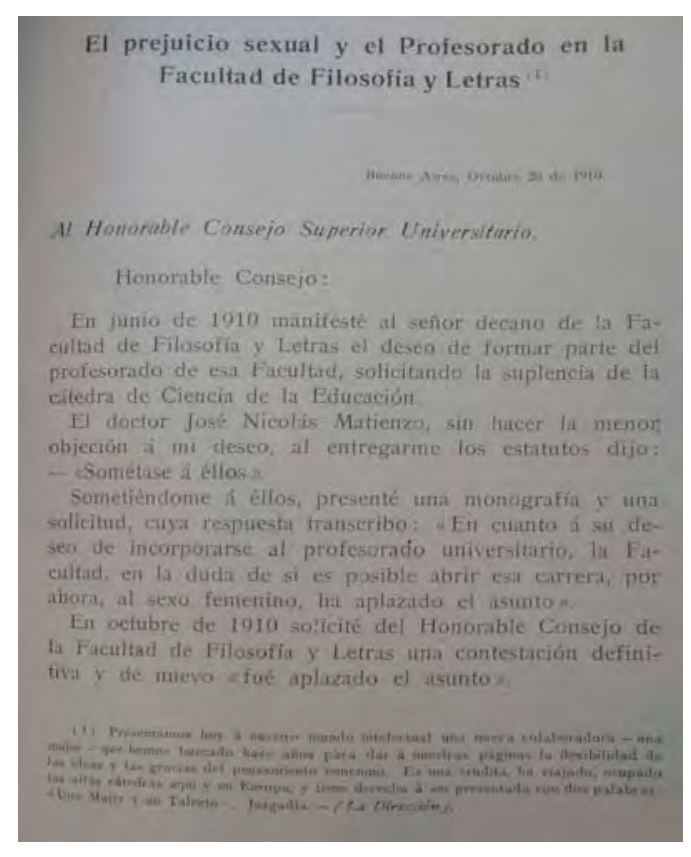

(Primera página del artículo de Raquel Camaña publicado por la Revista de Derecho, Historia y Letras en 1910. A pie de página, un detalle histórico.)

lograr que el "aquí" de aquella idea pudiese ser también un acá, y que su "ahora" no fuese sólo una determinación cronológica pasajera sino una verdadera progresividad. En su libro, Recuerdos de provincia, nos ha dejado una hermosa frase en la cual se resume el sueño mejor de aquella época: "En aquellos tiempos -dice-, el nuevo y el antiguo mundo estaban anillados por el pensamiento" 4. Por eso no debería sorprendernos que un joven Borges haya dicho -de Sarmiento- que "nos europeizó con su fe de hombre recién venido a la cultura y que espera milagros de ella" 5 , palabras éstas que algunos han entendido como un "ajuste de cuentas", pero en las cuales yo prefiero intuir, más bien, aquel romántico consuelo que a veces transmiten las causas perdidas. 
Y sin embargo, dicho así, sin más estadística que el hábito de la polémica, pareciera que hoy hubiese una especie de consenso general en que la persona de Sarmiento -así como su influencia- debiesen ser, entre nosotros, fuertemente cuestionadas; aunque -por supuesto- no se trata aquí de protestar contra la crítica, pues como la propia Camaña -recordando sus tiempos de colegiala- señalaría: "Cada curso normal tenía en el salón de clase una biblioteca de acuerdo con los programas: Aquellos libros no eran mero adorno: Les dedicábamos toda las horas de lectura, las vacantes por falta de profesor. Cada punto esencial de los programas era debatido de acuerdo con los hechos observados por nosotros, con las teorías más razonables que cada uno de los alumnos, dividiéndonos de antemano el trabajo, buscaba, rehacía, exponía y criticaba, sobre todo criticaba" 6 . El problema entonces (aunque más bien habría que decir: la paradoja) es pensar que si acaso fuese posible postular -históricamente- en la persona, la obra, el pensamiento de Camaña, una certificación del cumplimiento de aquella promesa que Sarmiento nos hacía al final de Recuerdos de provincia, cuando hablándonos de otro libro suyo (Educación popular) decía: "No sé qué crítico deploraba que no hubiese indicado los medios de hacer efectivas las observaciones y doctrinas en esta obra acumuladas. Una sola palabra bastaría a completarla y satisfacer este deseo. Denme patria donde me sea dado obrar, y les prometo convertir en hechos cada sílaba, y eso en poquísimos años"7; si acaso, decía, fuese posible comprobar esa promesa a través de aquel acontecimiento que es en sí Raquel Camaña (y que así dicho suena grandilocuente, pero que en realidad no tiene más grandilocuencia que aquella que podemos constatarle a cualquier pedacito de cotidianidad que logra salvarse del paso del tiempo); si acaso aquello fuese posible, entonces habría que preguntarse dónde están los acontecimientos que certificarían las toneladas y toneladas de tiempo (puesto que el tiempo es la verdadera convertibilidad de todo) que desde hace décadas vienen invirtiéndose en planificación educativa, ya que si no los hallásemos, entonces -más allá de nuestras humanas sensibilidades- haríamos bien en tratar de aprender algo todavía de Sarmiento, y esto es, al menos, su método.

III.

Es cierto que en la obra de Sarmiento hay páginas terribles; es cierto que ha escrito un libro maravillosamente intolerante en el cual el gaucho y la pampa son el enemigo, y que en otro libro suyo ha dicho de sí mismo: "Todo yo era una protesta contra el espíritu gauchesco" 8. Pero aquí, antes de entender demasiado pronto, habría que preguntarse qué entendía Sarmiento por "pampa", por "espíritu gauchesco". Después de todo, y tan sólo para dar un ejemplo trivial, hoy se hace de la palabra "turro" una evocación de juventud y amistad -y acaso también un sinónimo de viveza-, pero en los arrabales porteños, hace poco más de cien años, el "turro" era un "tipo tonto, idiota, o con malas intenciones"...9.

Por "pampa", por "Europa”, por "espíritu gauchesco", Sarmiento no entendía "pampa", "Europa” o "espíritu gauchesco". Entendía ideas, constelaciones; conceptos cuyos significados eran tan íntimos e intraducibles como lo son nuestras sendas visiones de mundo. Decir de Sarmiento que fue un traidor a la causa americana (es decir, a la causa de esta América, la latina) por su amor a Europa, es ignorar que Sarmiento no amaba en realidad a aquella Europa que era una "triste mezcla de grandeza i de abyección" 10 -como dijo, sino más bien a la idea de Europa que él mismo se había forjado y que era su imagen de lo más querido; es ignorar que en 1845 inició un viaje por aquella Europa, y que al desembarcar en el Havre comentó -decepcionado- que "no he podido desimpresionarme en dos días del mal efecto que me ha producido esta primera impresión"11. Y sin embargo, Sarmiento siguió amando a Europa; porque lo cierto es que él no pretendía tanto imponerle a América aquella Europa que está al otro lado del Atlántico como esa otra, más bien, que había nacido en su cabeza, y que acaso había encontrado esbozada -como un proyecto seductor, maleable- en los jóvenes Estados Unidos de América. ¿Hemos de lamentar ese turbamiento por una cultura que no ha sabido desembocar sino en la hegemonía mundial de una ideología que, sin lugar a dudas, se presenta hoy como la mayor expresión histórica de aquel anagrama que el propio Sarmiento supo encontrar en la palabra "argentino"? Recordemos, sin embargo, que los Estados Unidos que a Sarmiento le tocó en suerte visitar fueron los de Emerson, Thoreau, Whitman, y que si de pronto considerásemos que aquellos Estados Unidos fueron capaces de soñar venturas como esta: "En este país, la ciudad de- 
bería en ciertos aspectos ocupar el lugar de los nobles de Europa. Debería ser el patrón de las bellas artes" 12 , creo que comprenderíamos el fondo de ineducabilidad que estaba destinado también a Massachusetts.

De este modo, Europa no fue sólo un sueño para Sarmiento, pues Boston iba a ser aquella Europa... aunque aquí, ahora, tengamos que decir que sólo lo sería al modo de esas realidades que un día llegan -como diría Freud- sin avisar, para desrealizar toda una parte de nuestra memoria13.

En aquella Boston, "reina de las escuelas de enseñanza primaria" 14 , Sarmiento esperaba hallar un punto de capitón para sus viajes: "El principal objeto de mi viaje -decía- era ver a M. Horace Mann, el secretario del Board de Education, el gran reformador de la educación primaria, viajero como yo en busca de métodos i sistemas por Europa, i hombre que a un fondo inagotable de bondad i de filantropía, reunía en sus actos i sus escritos una rara prudencia i un profundo saber. Vivía fuera de Boston..."15.

Mentor de aquel proyecto normalista en los Estados Unidos, Sarmiento sabría convertir a Horace Mann en el norte de su propia obra pedagógica; pero no sólo a Mann, ya que luego de fallecido éste en 1859, su esposa, Mary Peabody, sostendría con Sarmiento una larga correspondencia que habría de prolongarse por décadas. Parte de la misma ha sido recopilada hace algunos años en un libro titulado My dear sir (ICANA, 2001), y aunque allí podamos echar de menos la voz de Sarmiento, lo cierto es que basta ese curioso soliloquio para descubrir que Mary Peabody fue quien recomendaría gran parte de las maestras que habrían de llegar a Argentina, y entre ellas a Mary Graham.

Así, pareciera que la historia fuese reacia a dejarse asir por primeras impresiones, y de ahí que cuando leemos a Sarmiento decir de Boston que "cuatro líneas de vapores lo ligan con la Europa" 16 , puede que debamos entender algo más que meras constataciones...

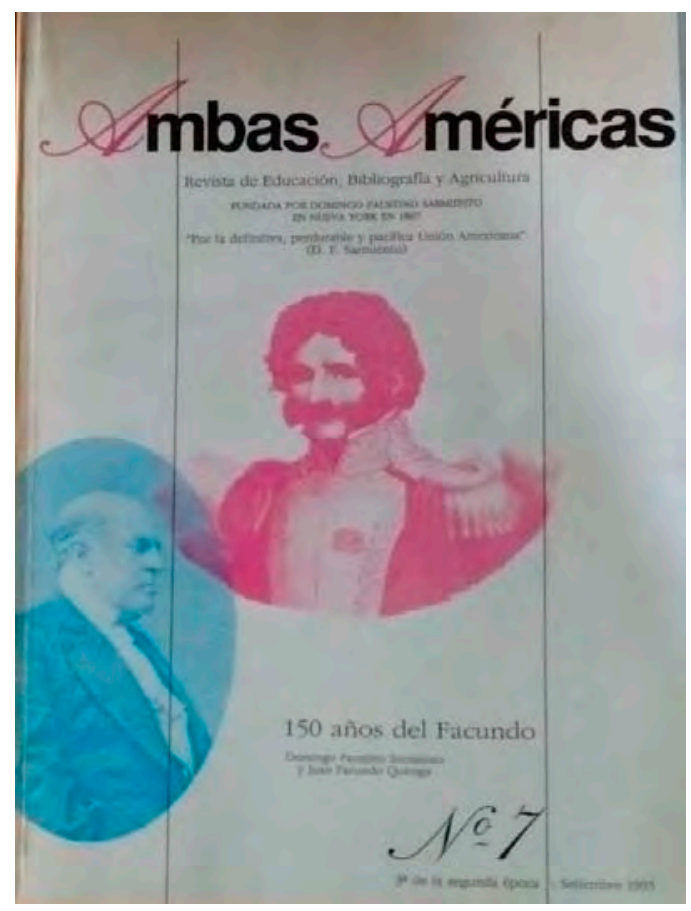

(Portada de Ambas Américas, No 7, revista fundada por Sarmiento en Nueva York, en 1867. Salieron bajo la dirección de Sarmiento los números 1,2,3 y 4, hasta 1868. A partir del № 5 (1992), es el órgano de difusión de la Asociación de Amigos del Museo Histórico Sarmiento en la ciudad de Buenos Aires.)

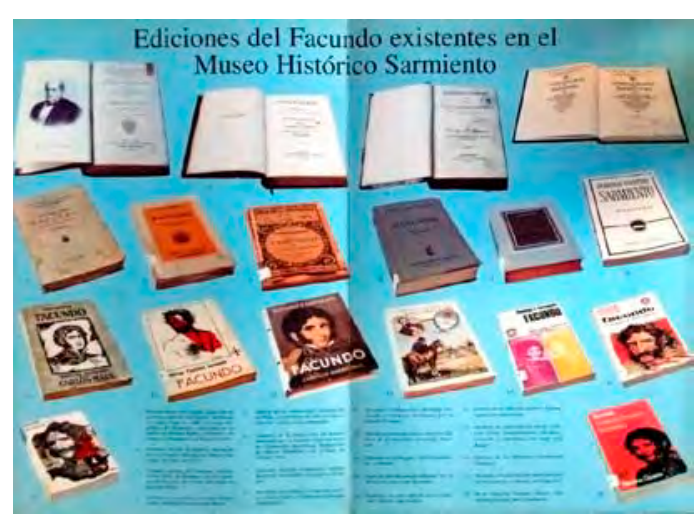

(Folleto homenaje al Facundo, en sus 150 años, en el No 7 de la revista Ambas Américas. En la segunda fila a la izquierda, atención al detalle de la preciosa edición de la UNLP de 1938, en homenaje a Sarmiento en el cincuentenario de su muerte.) 
IV.

La "pampa", entonces, no podía ser para Sarmiento sino lo otro del ensueño, la pesadilla: La pampa, como aquel Far West que no llegaría a conocer pero al respecto del cual escribiría que era invadido por "enjambres de colonizadores" que llevaban "las instituciones, la ciencia i la práctica del gobierno, el espíritu yankee i las artes manuales que presiden a la toma de posesión de la tierra"17; y de ahí que aunque Sarmiento -en el Facundo- fuese a describirla puntillosamente, sea preciso considerar que lo hizo a pesar de jamás haberla visto... ¿Nos engaña, entonces? Tanto como nos engañaría la poesía de Rafael Cansinos Assens, quien respondía: "Sí, espero verlo alguna vez", cada vez que alguien elogiaba sus versos sobre el mar.

Creo entonces que al lugar común de la diatriba bien podríamos anteponer un pensamiento: que a pesar de que nos gusta imaginar que existen tales cosas como un bien y un mal, y aunque más nos gusta pensar que ese bien y ese mal se encuentran separados por kilómetros de distancia, la civilización y la barbarie se entremezclan, pues existe siempre un resto de ineducabilidad que insiste más y más a cada embate educativo. Bioy Casares, en aquella reescritura del Facundo que fuera El sueño de los héroes, lo advertiría diciendo que "es notable cómo una mujer querida puede educarnos, por un tiempo"18.

Y acaso Sarmiento, al final, haya alcanzado algo de esa sabiduría: en 1885, tres años antes de su muerte, se encontró con un joven pariente de $\mathrm{Fa}$ cundo Quiroga (aquel "gaucho malo" de la pampa) mientras paseaba por el cementerio de La Recoleta. El joven, de apellido Arce, se jactó ante Sarmiento de no ir vestido ya como un bárbaro... y fue entonces que estando allí los dos, frente a la terrible tumba de Facundo, Sarmiento descubrió algo que nos es confesado así: "... mi sangre corre ahora confundida en sus hijos con la de Facundo, y no se han repelido sus corpúsculos rojos, porque eran afines" 19 . No, no puede matarse a las ideas... acaso sólo podamos resignarlas.
Notas

1. En: Revista de Derecho, Historia y Letras, tomo XXXVII, Ed. Jacobo Peuser, Bs. As., 1910, p. 596.

2. Citado por Tristán E. Guevara, en: "Las maestras norteamericanas que trajo Sarmiento", conferencia publicada por el Servicio cultural e informativo de los Estados Unidos de América, Bs. As., 1954, p. 16.

3. Camaña, Raquel: op. cit., p. 582.

4. Sarmiento, D. F.: Recuerdos de provincia, Ed. Salvat, España, 1970 , p. 88.

5. Borges, Jorge Luis: El tamaño de mi esperanza, Ed. Seix Barral, Bs. As., 1993, p. 12.

6. Camaña, Raquel: op. cit., p. 580-581.

7. Sarmiento, D. F.: Recuerdos de provincia, op. cit., p. 167.

8. Sarmiento, D. F.: Campaña en el Ejército Grande, Ed. Kraft, Bs. As., 1957, p. 158.

9. Sábato, Ernesto: Tango, discusión y clave, Ed. Losada, Bs. As., 2005, p. 220

10. Sarmiento, D. F.: Viajes por Europa, África y América (18451847) y Diario de gastos, Ed. Fondo de Cultura Económica, Bs. As., 1993, p. 86.

11. Ibid.

12. Thoreau Henry David: Walden, Ed. Cátedra, Madrid, 2009, p. 154. 13. Freud, S.: "Un trastorno de la memoria en la Acrópolis", en: Obras completas, volumen III, Ed. Biblioteca Nueva, Madrid, 1968.

14. Sarmiento, D. F.: Viajes por Europa, África y América, op. cit., p. 373.

15. Ibíd., p. 388.

16. Ibíd., 387.

17. Ibíd.

18. Casares, Adolfo Bioy: El sueño de los héroes, Ed. Emecé, Bs. As., 1999, p. 122.

19. Sarmiento, D. F.: "El día de los muertos", diario El Debate, 4 de noviembre de 1885. Revista Ambas Américas. Revista de Educación, Bibliografía y Agricultura, $N^{\circ}$ 7, Bs. As., Septiembre de 1995 , p. 85 . 